\title{
Relapse rate and renal prognosis in ANCA-associated vasculitis according to long-term ANCA patterns.
}

\author{
Joaquim Oristrell ${ }^{1}$, José Loureiro-Amigo ${ }^{2}$, Roser Solans ${ }^{2}, \mathrm{M}^{\mathrm{a}}$ Pau Valenzuela ${ }^{1}$, Víctor \\ Monsálvez ${ }^{1}$, Alfons Segarra-Medrano ${ }^{3}, \mathrm{M}^{\mathrm{a}}$ José Amengual $^{1}$, Ana Marín ${ }^{3}$, Carlos Feijoo ${ }^{1}$, \\ and Carles Tolosa ${ }^{1}$ \\ ${ }^{1}$ Consorci Corporació Sanitària Parc Taulí \\ ${ }^{2}$ Hospital Vall d'Hebron \\ ${ }^{3}$ Vall d'Hebron Hospital Universitari
}

August 11, 2020

\begin{abstract}
Introduction: long-term observation of patients with ANCA-associated vasculitis (AAV) allows the identification of different longitudinal patterns of ANCA levels during follow-up. This study aimed to characterise these patterns and to determine their prognostic significance. Methods: all ANCA determinations performed in two university hospitals along a 2-year period were retrospectively reviewed. Patients were included in the analysis if they had high titers of anti-myeloperoxidase (anti-MPO) or anti-proteinase 3 (anti-PR3) antibodies at least once, they had [?]5 serial ANCA determinations, and they had AAV diagnosed by biopsy or ACR classification criteria. Patients' time-course ANCA patterns were classified as monophasic, remitting, recurrent or persistent. Associations between ANCA patterns and prognostic variables (relapse rate and renal outcome) were analysed by univariate and multivariate statistics. Results: A total of 99 patients (55 with microscopic polyangiitis [MPA], 36 with granulomatosis with polyangiitis [GPA], and 8 with eosino $\neg$ philic granulomatosis with polyangiitis) were included. Median follow-up was 9 years. Among patients diagnosed with MPA or GPA, recurrent or persistent ANCA patterns were associated with a higher risk of clinical relapse (HR 3.7 [95\% CI 1.5-9.1] and HR 2.9 [95\% CI 1.1-8.0] respectively), independently of clinical diagnosis or ANCA specificity. In patients with anti-MPO antibodies, the recurrent ANCA pattern was associated with worsening renal function (OR 5.7 [95\% CI 1.2-26.0]). Conclusion: Recurrent or persistent ANCA patterns are associated with a higher risk of clinical relapse. A recurrent ANCA pattern was associated with worsening renal function in anti-MPO-associated vasculitis.
\end{abstract}

Relapse rate and renal prognosis in ANCA-associated vasculitis according to long-term ANCA patterns.

Short title: long-term ANCA patterns and prognosis of systemic vasculitis

Joaquim Oristrell*. Internal Medicine Service. Parc Tauli Hospital Universitari. Institut d'Investigació i Innovació Parc Taulí I3PT. Universitat Autònoma de Barcelona. Sabadell, Catalonia.

José Loureiro-Amigo. Internal Medicine Service. Hospital Universitari Vall d'Hebrón. Universitat Autònoma de Barcelona. Barcelona, Catalonia.

Roser Solans. Internal Medicine Service. Hospital Universitari Vall d'Hebrón. Universitat Autònoma de Barcelona. Barcelona, Catalonia.

Ma․ Pau Valenzuela. Nephrology Service. Parc Tauli Hospital Universitari. Institut d'Investigació i Innovació Parc Taulí I3PT. Universitat Autònoma de Barcelona. Sabadell, Catalonia. 
Víctor Monsálvez. Internal Medicine Service. Parc Tauli Hospital Universitari. Institut d'Investigació i Innovació Parc Taulí I3PT. Universitat Autònoma de Barcelona. Sabadell, Catalonia.

Alfons Segarra. Nephrology Service. Hospital Universitari Vall d'Hebrón. Universitat Autònoma de Barcelona. Barcelona, Catalonia.

Ma․ José Amengual. Immunology Service. Parc Tauli Hospital Universitari. Institut d'Investigació i Innovació Parc Taulí I3PT. Universitat Autònoma de Barcelona. Sabadell, Catalonia.

Ana Marín. Immunology Service. Hospital Universitari Vall d'Hebrón. Universitat Autònoma de Barcelona. Barcelona, Catalonia.

Carlos Feijoo. Internal Medicine Service. Parc Tauli Hospital Universitari. Institut d'Investigació i Innovació Parc Taulí I3PT. Universitat Autònoma de Barcelona. Sabadell, Catalonia.

Carles Tolosa. Internal Medicine Service. Parc Tauli Hospital Universitari. Institut d'Investigació i Innovació Parc Taulí I3PT. Universitat Autònoma de Barcelona. Sabadell, Catalonia.

*Corresponding author: Joaquim Oristrell, MD, PhD. Servei de Medicina Interna. Parc Tauli Hospital Universitari. Institut d'Investigació i Innovació Parc Taulí I3PT. Universitat Autònoma de Barcelona. Sabadell, Catalonia.mail:joristrell@tauli.cat

Key words: antineutrophil cytoplasmic antibodies, vasculitis, renal failure, prognosis

\section{Summary:}

Introduction: long-term observation of patients with ANCA-associated vasculitis (AAV) allows the identification of different longitudinal patterns of ANCA levels during follow-up. This study aimed to characterise these patterns and to determine their prognostic significance.

Methods: all ANCA determinations performed in two university hospitals along a 2-year period were retrospectively reviewed. Patients were included in the analysis if they had high titers of anti-myeloperoxidase (anti-MPO) or anti-proteinase 3 (anti-PR3) antibodies at least once, they had [?]5 serial ANCA determinations, and they had AAV diagnosed by biopsy or ACR classification criteria. Patients' time-course ANCA patterns were classified as monophasic, remitting, recurrent or persistent. Associations between ANCA patterns and prognostic variables (relapse rate and renal outcome) were analysed by univariate and multivariate statistics.

Results: A total of 99 patients (55 with microscopic polyangiitis [MPA], 36 with granulomatosis with polyangiitis [GPA], and 8 with eosinophilic granulomatosis with polyangiitis) were included. Median followup was 9 years. Among patients diagnosed with MPA or GPA, recurrent or persistent ANCA patterns were associated with a higher risk of clinical relapse (HR 3.7 [95\% CI 1.5-9.1] and HR 2.9 [95\% CI 1.1-8.0] respectively), independently of clinical diagnosis or ANCA specificity. In patients with anti-MPO antibodies, the recurrent ANCA pattern was associated with worsening renal function (OR 5.7 [95\% CI 1.2-26.0]).

Conclusion: Recurrent or persistent ANCA patterns are associated with a higher risk of clinical relapse. A recurrent ANCA pattern was associated with worsening renal function in anti-MPO-associated vasculitis.

\section{Introduction}

Anti-neutrophil cytoplasmic antibody (ANCA)-associated vasculitis comprises a heterogeneous group of vasculitides characterised by inflammation and necrosis of small and medium-sized vessels, usually associated with autoantibodies directed against neutrophil lysosomal enzymes (1).

Consensus statements on testing methods, clinical indications and interpretation of ANCA tests have been published (2). However, the usefulness of monitoring ANCA levels in the clinical follow-up of AAV is still a matter of debate. Most studies have focused on analysing the sensitivity, specificity, and predictive value of an increase in ANCA levels to predict clinical relapses. The results of these studies vary widely, probably related to the heterogeneity of the vasculitides included, the criteria used to define an increase in ANCA 
titres, and the criteria used to define a clinical relapse (3). At present, most clinicians continue to routinely monitor ANCA levels, although several studies have claimed that there is no need to perform such serial measurements since they have a low sensitivity and specificity to predict a clinical relapse (4-7).

Long-term observation of patients with AAV allows the identification of different patterns of ANCA titers during follow-up. Some patients will display a monophasic pattern, with an initial peak of antibodies that later become negative, while others will present persistent low levels, or recurrent peaks, or will remain with persistently high ANCA levels. The present study aimed to characterise these longitudinal patterns and to determine their clinical assocations and possible prognostic impact.

\section{Methods}

After obtaining the approval of the clinical research ethics committees, we reviewed all ANCA determinations performed by the Immunology Service of Parc Tauli Hospital Universitari (PTHU) and by the Immunology Service at Hospital Universitari Vall d'Hebron (HUVH) from January 2014 through December 2015.

Patients were eligible for inclusion if they met the following three criteria: 1) had a biopsy compatible with the diagnosis of MPA, GPA, or EGPA, or met the American College of Rheumatology classification criteria for GPA (8) or EGPA (9) without an alternative clinical diagnosis; 2) had positive anti-MPO or anti-PR3 antibodies with titers [?]20 U/ml at least once; and 3) had at least 5 serial ANCA determinations from the date of diagnosis until December 2017. We excluded patients who did not complete 6 months of follow-up, patients with vasculitis limited to the skin or associated with cocaine abuse, and patients with insufficient clinical information.

ANCA titers were determined in serum by indirect immunofluorescence both on ethanol and on formalin-fixed human neutrophils smeared onto glass slides (Granulocyte Mosaic 13 EUROIMMUN, Lubeck, Germany). All ANCA-positive samples were analysed for anti-MPO and anti-PR3 antibodies by capture ELISA techniques (ImmunoCAP(r) 250 Phadia AB, Thermo Fisher Scientific, Uppsala, Sweden) or chemiluminescence (QUANTA Flash MPO / PR3, INOVA diagnostics, San Diego, California, USA).

Full details of the presenting illness, clinical relapses, and treatments carried out during follow-up were collected from case records. Clinical relapse was defined as a new or worsened manifestation of AAV that required a change in therapy.

Worsening renal function was defined as an increase in serum creatinine [?]1.5 times from baseline during follow-up. End-stage renal disease (ESRD) was defined as the need for sustained renal replacement therapy.

Four longitudinal patterns of ANCA levels were defined: 1) Monophasic pattern: initial peak of anti-PR3 or anti-MPO antibodies with subsequent negative results; 2) Remitting pattern: initial peak of anti-PR3 or anti-MPO antibodies followed by persistent low ANCA levels $(<20 \mathrm{U} / \mathrm{ml}) ; 3)$ Recurrent ANCA pattern: at least two successive peaks of anti-PR3 or anti-MPO antibodies ([?]20 U/ml) on follow-up, with periods of negative results; and 4) Persistent ANCA pattern: sustained positive anti-PR3 or anti-MPO antibodies (> $20 \mathrm{U} / \mathrm{ml}$ ) throughout follow-up.

Associations between ANCA patterns and clinical variables were analysed using univariate statistics (Student's t or Mann-Whitney U tests, as appropriate, for continuous variables and Chi-square or Fisher's exact test for dichotomous variables). The association between ANCA patterns and clinical relapses or worsening renal function were analysed using Kaplan Meier curves and Cox proportional hazards model. P-values < 0.05 were considered statistically significant. All statistical analyses were carried out using SPSS version 23.0 for Windows (SPSS, Chicago, IL, USA).

\section{Results}

A total of 121 patients met the inclusion criteria; Eighteen patients were excluded because of insufficient clinical information $(n=9)$, early death $(n=5)$, vasculitis limited to the skin $(n=4)$, non-classifiable vasculitis $(n=2)$ or vasculitis associated with cocaine abuse $(n=2)$. Thus, 99 patients were finally included in the analyses. 
Table 1 summarises the clinical characteristics of the patients included in the study. Patients' mean age at diagnosis was 56.5 years and median follow-up was 9 years. Overall, 55 patients were diagnosed with MPA, 36 with GPA, and 8 with EGPA. Out of 99 patients, 67 (68\%) were positive for anti-MPO antibodies and $32(32 \%)$ for anti-PR3 antibodies.

All but one of the patients with anti-PR3 antibodies were diagnosed with GPA. Compared to patients with anti-MPO antibodies, those with anti-PR3 antibodies were younger and had a higher prevalence of purpura, arthritis, pulmonary infiltrates or nodules and eye-nose-throat (ENT) or ocular involvement. Patients with anti-PR3 antibodies had a higher rate of clinical relapses but lower mortality than patients with anti-MPO antibodies. Patients with anti-MPO antibodies were characterised by a higher prevalence of microhematuria, renal failure, and ESRD than patients with anti-PR3 antibodies (Table 1).

Time-course analysis of ANCA levels identified 26 (26.3\%) patients with monophasic pattern; 13 patients (13.1\%) with remitting pattern; 39 patients $(39.4 \%)$ with recurrent pattern; and 21 patients $(21.2 \%)$ with persistent ANCA pattern. Clinical characteristics, diagnosis, ANCA specificity, treatment administered and outcome according to ANCA patterns are shown in Table 2.

Patients with a monophasic o remitting ANCA pattern were more commonly diagnosed with MPA and had a higher prevalence of anti-MPO antibodies. These patients more often presented with ESRD at baseline and had received plasmapheresis more commonly than patients with a recurrent or persistent ANCA pattern (Table 2).

\section{Association between longitudinal ANCA patterns and risk of clinical relapse}

The proportion of patients who developed a clinical relapse was similar in patients with recurrent or persistent ANCA patterns $(34 / 39 ; 87.2 \%$ vs. $15 / 21 ; 71.4 \% ; \mathrm{p}=0.13)$. These relapse rates were much higher than those observed in patients with monophasic or remitting ANCA patterns $(6 / 29 ; 23.1 \%$ and 4/13;30.8\% respectively)(Table 2). Because of these similarities, in some analyses the four subsets were joined into two groups, the recurrent/persistent (R/P) pattern and the monophasic/remitting (M/R) pattern (Fig 1).

In the univariate analysis, other variables associated with an increased risk of clinical relapse were the diagnosis of GPA, the anti-PR3 specificity, the presence of arthritis, ENT or ocular involvement, and having received treatment with azathioprine, methotrexate or rituximab. Clinical features such as renal failure were associated with a lower risk of clinical relapse (Table 3).

In the multivariate Cox regression analysis, the recurrent or persistent ANCA patterns together with the presence of arthritis or ocular involvement, the absence of fever or having received rituximab treatment were independently associated with a higher risk of clinical relapse. Neither the clinical diagnosis, nor the antigenic specificity were associated with an increased risk of clinical relapse (Table 4).

\section{Association between longitudinal ANCA patterns and renal prognosis}

In our series, 21 out of 26 patients with worsening renal function, 10 out of 11 patients with ESRD during follow-up, and 7 out of 8 patients with ESRD at baseline had anti-MPO antibodies (Table 1).

Due to the scarcity of patients with anti-PR3 AAV who developed renal failure in our series, we focused our analysis of renal outcomes on patients with anti-MPO antibodies, regardless they were diagnosed with GPA or MPA. In the univariate analysis, we found that patients with arthritis, fever or constitutional symptoms had a lower risk of worsening renal function than patients without these clinical manifestations (Table 5). In addition, patients with the combined $\mathrm{R} / \mathrm{P}$ pattern had significantly worse renal prognosis than patients with the combined M/R pattern (Fig 2).

In the multivariate Cox regression analysis, both the recurrent ANCA pattern, or the combined R/P ANCA pattern were associated with an increased risk of worsening renal failure. The presence of arthritis or constitutional symptoms were associated with better renal outcomes. Neither the clinical diagnosis, nor the antigenic specificity were associated with an increased risk of worsening renal failure (Table 6). 


\section{Discussion}

In this study we have defined four time-course ANCA patterns and we observed an increased risk of clinical relapse in patients with a recurrent or persistent ANCA pattern, independently of the clinical diagnosis or the antigenic specificity.

The presence of anti-PR3 antibodies has long been associated with an increased risk of clinical relapse $(1,10,11)$. However, in our cohort, the recurrent or persistent ANCA patterns were associated with an increased risk of relapse, regardless of the ANCA antigenic specificity. These results are in keeping with other studies showing that patients with AAV and recurrent high anti-MPO antibodies are also at increased risk of clinical relapse $(12,13)$, and by the observation of Kemna et al showing that the association of an ANCA rise with a relapse was influenced by persistence of ANCA and not by ANCA antigenic specificity (14). Our results do not support the opinion of some authors claiming that there is no need in routinely monitoring ANCA titres in patients with ANCA-associated vasculitis (7).

We have also found that patients with anti-MPO vasculitis and a recurrent ANCA pattern were more prone to worsening renal function. It is generally accepted that patients with anti-MPO antibodies have a worse renal prognosis and a higher risk of progression to ESRD than patients with anti-PR3 antibodies (11,15-21), although not all studies have confirmed this association (22-24). Patients with anti-MPO antibodies usually have more glomerulosclerosis and interstitial fibrosis on renal biopsies than patients with anti-PR3 antibodies $(18,20,22,24)$. Some authors have suggested that these chronic lesions could result from a more protracted course and a greater diagnostic delay in anti-MPO AAV patients, meaning that on starting treatment they would have more irreversible chronic renal lesions than anti-PR3 AAV patients $(18,20,22)$. Our results, showing a lower decline of renal function in anti-PR3 patients despite being immunologically active, do not support this hypothesis. Conversely, it is likely that inflammatory lesions of patients with anti-MPO antibodies would have a greater tendency to residual fibrosis, as suggested both in experimental studies (25), and in clinical observations showing an increased risk of lung fibrosis in patients with anti-MPO antibodies $(26,27)$.

Other factors that have been associated with renal prognosis in AAV are advanced age (16), renal failure at disease onset $(16,19)$, and presence of tubular atrophy $(16)$. The importance of the longitudinal ANCA patterns on renal survival has been scarcely investigated. A small retrospective study by Franssen et al (28) found similar results to ours, with persistently high anti-MPO levels leading to chronic renal failure. Our series, with a larger number of patients with anti-MPO AAV, provides original data in this regard, showing a worse renal prognosis in patients with recurrent or persistent high anti-MPO-antibody levels.

The present study provides new information on the prognosis of AAV according to ANCA patterns, but several limitations should be mentioned. This is a retrospective observational study, so the clinical follow-up and treatments administered were not uniform. However, we performed a multivariate analyses and none of the administered treatments had a significant impact on the associations that have been described.

In conclusion, our study suggests that patients with a recurrent or persistent ANCA pattern have a higher risk of clinical relapse than patients with a monophasic or remitting pattern. In addition, patients with anti-MPO antibodies and a recurrent ANCA pattern had worse renal prognosis. Our results would suggest that a more aggressive treatment may be needed in these patients in order to preserve their renal function.

\section{Aknowledgements:}

Joan Carles Oliva, MStats Institut d'Investigacio i Innovacio Parc Tauli I3PT. Universitat Autonoma de Barcelona. Sabadell, Catalonia.

\section{Conflict of interest:}

The author declare they have not any conflict of interest.

\section{References:}


1.-Cornec D, Cornec-Le Gall E, Fervenza F, Specks U. ANCA-associated vasculitis - clinical utility of using ANCA specificity to classify patients. Nat Rev Rheumatol 2016;12:570-579.

2.-Bossuyt X, Cohen Tervaert JW, Arimura Y, Blockmans D, Flores-Suarez LF, Guillevin L et al. Revised 2017 international consensus on testing of ANCAs in granulomatosis with polyangiitis and microscopic polyangiitis. Nature Rev Rheumatol 2017;13:683-692.

3.-Birck R, Schmitt WH, Kaelsch IA, van der Woude FJ. Serial ANCA Determinations for monitoring disease activity in patients with ANCA-associated vasculitis: systematic review. Am J Kidney Dis 2005;47:15-23.

4.-Kerr GS, Fleisher TA, Hallahan CW, Leavitt RY, Fauci AS, Hoffman GS. Limited prognostic value of changes in antineutrophil cytoplasmic antibody titer in patients with Wegener's granulomatosis. Arthritis Rheum 1993;36:365-371.

5.-Davenport A, Lock RJ, Wallington T. Clinical significance of the serial measurement of autoantibodies to neutrophil cytoplasm using a standard indirect immunofluorescence test. Am J Nephrol 1995;15:201-207.

6.-Finkielman JD, Lee AS, Hummel AM, Viss MA, Jacob GL, Homburger HA, et al. ANCA are detectable in nearly all patients with active severe Wegener's granulomatosis. Am J Med 2007;120:643.e9-643.e14.

7.-Verstockt B, Bossuyt X, Vanderschueren S, Blockmans D. There is no benefit in routinely monitoring ANCA titers in patients with granulomatosis with polyangiitis. Clin Exp Rheumatol 2015; 33: S72-S76.

8.-Leavitt RY, Fauci AS, Bloch DA, Michel BA, Hunder GG, Arend WP, et al. The American College of Rheumatology 1990 criteria for the classification of Wegener's granulomatosis. Arthritis Rheum 1990;33:1101-1107.

9.-Masi AT, Hunder GG, Lie JT, Michel BA, Bloch DA, Arend WP, et al. The American college of rheumatology 1990 criteria for the classification of Churg-Strauss syndrome. Arthritis Rheum 1990;33:1094-1100.

10.-Kyndt X, Reumaux D, Bridoux F, et al. Serial Measurements of Antineutrophil cytoplasmic autoantibodies in patients with systemic vasculitis. Am J Med. 1999;106:527-533.

11.-Lionaki S, Blyth ER, Hogan SL, Hu Y, Senior BA, Jennette CE et al.

Classification of antineutrophil cytoplasmic autoantibody vasculitides: the role of antineutrophil cytoplasmic autoantibody specificity for myeloperoxidase or proteinase 3 in disease recognition and prognosis. Arthritis Rheum 2012;64:3452-3462.

12.-Terrier B, Saadoun D, Sene D, Ghillani P, Amoura Z, Deray G et al. Antimyeloperoxidase antibodies are a useful marker of disease activity in antineutrophil cytoplasmic antibody-associated vasculitides. Ann Rheum Dis 2009;68:1564-1571.

13.-Tomasson G, Grayson PC, Mahr AD, LaValley M, Merkel PA. Value of ANCA measurements during remission to predict a relapse of ANCA-associated vasculitis - a meta-analysis. Rheumatology 2012; 51: 100-109.

14.-Kemna MJ, Damoiseaux J, Austen J, et al. ANCA as a predictor of relapse: useful in patients with renal involvement but not in patients with nonrenal disease. J Am Soc Nephrol 2015;26:537-542.

15.-Robson J, Doll H, Suppiah R, Flossmann O, Harper L, Hoglund P et al. Damage in the ANCA-associated vasculitides: long-term data from the European Vasculitis Study group (EUVAS) therapeutic trials. Ann Rheum Dis 2015;74: 177-184.

16.-Tanna A, Guarino L, Tam FWK, Rodriquez-Cubillo B, Levy JB, Cairns TD et al. Long-term outcome of anti-neutrophil cytoplasm antibody-associated glomerulonephritis: evaluation of the international histological classification and other prognostic factors. Nephrol Dial Transplant 2015;30:1185-1192. 
17.-Mohammad AJ, Segelmark M. A population-based study showing better renal prognosis for proteinase 3 antineutrophil cytoplasmic antibody (ANCA)-associated nephritis versus myeloperoxidase ANCA-associated nephritis. J. Rheumatol 2014;41:1366-1373

18.-Vizjak A, Rott T, Koselj-Kajtna M, Rozman B, Kaplan-Pavlovcic S, Ferluga D. Histologic and immunohistologic study and clinical presentation of ANCA-associated glomerulonephritis with correlation to ANCA antigen specificity. Am J Kidney Dis 2003;41:539-549.

19.-de Joode AAE, Sanders J SF, Stegeman CA. Renal survival in proteinase 3 and myeloperoxidase ANCAassociated systemic vasculitis. Clin J Am Soc Nephrol 2013; 8:1709-1717.

20.-Quintana LF, Perez NS, De Sousa E, Rodas LM, Griffiths MH, Sole M et al. ANCA serotype and histopathological classification for the prediction of renal outcome in ANCAassociated glomerulonephritis. Nephrol Dial Transplant 2014; 29:1764-1769.

21.-Sada KE, Yamamura M, Harigai M, Fujii T, Takasaki Y, Amano K, et al. Different responses to treatment across classified diseases and severities in Japanese patients with microscopic polyangiitis and granulomatosis with polyangiitis: a nationwide prospective inception cohort study. Arthritis Res Ther 2015; 17: 305.

22.-Franssen CFM, Gans ROB, Arends AJ, Hageluken C, ter Wee PM, Gerlag PGG et al. Differences between anti-myeloperoxidase-and anti-proteinase 3 associated renal disease. Kidney Int 1995; 47:193-199.

23.-Westman KW, Bygren PG, Olsson H, Ranstam J, Wieslander J. Relapse rate, renal survival, and cancer morbidity in patients with Wegener's granulomatosis or microscopic polyangiitis with renal involvement. J Am Soc Nephrol 1998;9:842-852.

24.-Marco H, Draibe, Villacorta J, Quintana LF, Martin N, Garcia-Osuna N et al. Determinants of renal and patient outcomes in a Spanish cohort of patients with ANCA-associated vasculitis and renal involvement. Clinical Rheumatology. doi.org/10.1007/s10067-017-3973-3982.

25.-Guilpain P, Chereau C, Goulvestre C, Servettaz A, Montani D, Tamas N et al. The oxidation induced by antimyeloperoxidase antibodies triggers fibrosis in microscopic polyangiitis. Eur Respir J 2011; 37: 15031513

26.Tzelepis GE, Kokosi M, Tzioufas A, Toya SP, Boki KA, Zormpala A et al. Prevalence and outcome of pulmonary fibrosis in microscopic polyangiitis. Eur Respiratory J 2010 36: 116-121.

27.-Comarmond C, Crestani B, Tazi A, Hervier B, Adam-Marchand S, Nunes H et al. Pulmonary fibrosis in antineutrophil cytoplasmic antibodies (ANCA)- associated vasculitis: a series of 49 patients and review of the literature. Medicine (Baltimore) 2014;93:340-349.

28.-Franssen CFM, Stegeman CA, Oost-Kort WW, Kallenberg CGM, Limburg PC, Tiebosch A et al. Determinants of renal outcome in anti-myeloperoxidase-associated necrotizing crescentic glomerulonephritis. J Am Soc Nephrol 1998;9:1915-1923.

Table 1. Clinical characteristics and outcome of ANCA-associated vasculitis according to antigenic specificity.

Table 2. Clinical characteristics and outcome of ANCA-associated vasculitis according to ANCA pattern

Table 3. Variables associated with clinical relapses in GPA amd MPA

Table 4. Variables associated with clinical relapses in GPA and MPA. Multivariate analysis.

Table 5. Variables associated with worsening renal failure in anti-MPO vasculitis. Univariate analysis.

Table 6. Variables associated with worsening renal failure in anti-MPO vasculitis. Multivariate analysis

Fig 1. Clinical relapse according to ANCA pattern in GPA and MPA. A: all ANCA vasculitis; B: anti-PR3 vasculitis; $\mathrm{C}$ : anti-MPO vasculitis.

Fig 2. Worsening renal failure according to ANCA pattern in GPA or MPA anti-MPO vasculitis. 
Table 1. Clinical characteristics and outcome of ANCA-associated vasculitis according to antigenic specificity

\begin{tabular}{|c|c|c|c|c|}
\hline & Total $(\mathrm{n}=99)$ & Anti-MPO $(\mathrm{n}=67)$ & Anti-PR3 $(\mathrm{n}=32)$ & $\mathrm{p}^{\mathrm{b}}$ \\
\hline $\begin{array}{l}\text { Age, yrs, mean } \\
\text { (SD) Female } \\
\text { sex, n (\%) }\end{array}$ & $\begin{array}{l}56.5(16.8) 48 \\
(48.5)\end{array}$ & $\begin{array}{l}61.3(14.6) 34 \\
(50.7)\end{array}$ & $\begin{array}{l}46.4(17.0) 14 \\
(43.8)\end{array}$ & $<0.001 \mathrm{NS}$ \\
\hline $\begin{array}{l}\text { Diagnosis MPA, } \\
\text { n (\%) GPA, n } \\
(\%) \text { EGPA, n (\%) }\end{array}$ & $\begin{array}{l}55(55.6) 36 \\
(36.4) 8(8.1)\end{array}$ & $\begin{array}{l}54(80.6) 5(7.5) 8 \\
(11.9)\end{array}$ & $\begin{array}{l}1(3.1) 31(96.9) 0 \\
(0)\end{array}$ & $\begin{array}{l}<0.001<0.001 \\
0.05\end{array}$ \\
\hline $\begin{array}{l}\text { Time-course } \\
\text { ANCA pattern } \\
\text { Monophasic, } \mathrm{n} \\
\text { (\%) Remitting, n } \\
\text { (\%) Persistent, n } \\
\text { (\%) Recurrent, } \mathrm{n} \\
\text { (\%) }\end{array}$ & $\begin{array}{l}26(26,3) 13 \\
(13,1) 21(21,2) \\
39(39,4)\end{array}$ & $\begin{array}{l}23(34.3) 11 \\
(16.4) 9(13.4) 24 \\
(35.8)\end{array}$ & $\begin{array}{l}3(9.4) 2(6.3) 12 \\
(37.5) 15(46.9)\end{array}$ & $\begin{array}{l}0.008 \text { NS } 0.006 \\
\text { NS }\end{array}$ \\
\hline Clinical & $72(72.7) 54$ & $47(70.1) 36$ & $25(78.1) 18$ & NS NS NS 0.006 \\
\hline features & $(54.5) 84(84.8)$ & $(53.7) 56(83.6)$ & $(56.3) 28(87.5)$ & $<0.001$ NS 0.04 \\
\hline $\begin{array}{l}\text { Constitutional } \\
\text { svmptoms, }(\%)\end{array}$ & $\begin{array}{l}68(68.7) 60 \\
(60.6) 28(28.3)\end{array}$ & $\begin{array}{l}52(77.6) 49 \\
(73.1) 19(28.4)\end{array}$ & $\begin{array}{l}16(50.0) 11 \\
(34.4) 9(28.1) 11\end{array}$ & $\begin{array}{l}<0.001 \mathrm{NS} N \mathrm{NS} \\
<0.0010 .03\end{array}$ \\
\hline Fever, n (\%) & $22(22.2) 20$ & $11(16.4) 2(3.0)$ & $(34.4) 18(56.3) 5$ & $<0.0010 .05$ \\
\hline Anemia, n (\%) & (20.2) 16 (16.2) & $11(16.4) 2(3.0) 9$ & (15.6) $3(9.4) 24$ & \\
\hline Microhaematuria, & (5.1) $33(33.3) 14$ & $(13.4) 6(9.0) 25$ & $(75.0) 8(25.0) 24$ & \\
\hline n (\%) Renal & (14.1) $49(49.5)$ & $(37.3) 4(6.0)$ & $(75.0) 6(18.8)$ & \\
\hline failure, n (\%) & $10(10.1)$ & & & \\
\hline \\
\hline \multicolumn{5}{|l|}{ haemorrhage, n } \\
\hline \multicolumn{5}{|l|}{ (\%) Pulmonary } \\
\hline \multicolumn{5}{|l|}{ infiltrates, n (\%) } \\
\hline \multirow{2}{*}{\multicolumn{5}{|c|}{$\begin{array}{l}\text { Pulmonary } \\
\text { nodules, n (\%) }\end{array}$}} \\
\hline & & & & \\
\hline \multirow{2}{*}{\multicolumn{5}{|c|}{$\begin{array}{l}\text { Mononeuritis } \\
\text { multiplex, n (\%) }\end{array}$}} \\
\hline & & & & \\
\hline CNS involvement, & & & & \\
\hline & & & & \\
\hline \multicolumn{5}{|l|}{ involvement, $\mathrm{n}$} \\
\hline \multicolumn{5}{|l|}{ (\%) Purpura, n } \\
\hline \multicolumn{5}{|l|}{ (\%) Arthritis, n } \\
\hline (\%) Ocular & & & & \\
\hline $\begin{array}{l}\text { involvement, } \mathrm{n} \\
(\%)\end{array}$ & & & & \\
\hline
\end{tabular}






a [?]1 clinical relapses during follow-up. ${ }^{\mathrm{b}}$ Chi square (categoric variables) or Student's t (continuous variables). NS: not significant. Anti-MPO: anti-myeloperoxidase. Anti-PR3: anti-proteinase-3. MPA: microscopic polyangiitis. GPA: granulomatosis with polyangiitis. EGPA: eosinophilic granulomatosis with polyangiitis. ESRD: end-stage renal disease. IQR: interquartile range. ENT: ear, nose, throat. CNS: central nervous system.

Table 2. Clinical characteristics and outcome of ANCA-associated vasculitis according to ANCA pattern

\begin{tabular}{|c|c|c|c|c|c|}
\hline & $\begin{array}{l}\text { Monophasic } \\
(\mathrm{n}=26)\end{array}$ & $\begin{array}{l}\text { Remitting } \\
(\mathrm{n}=13)\end{array}$ & $\begin{array}{l}\text { Persistent } \\
(\mathrm{n}=21)\end{array}$ & $\begin{array}{l}\text { Recurrent } \\
(\mathrm{n}=39)\end{array}$ & $\mathrm{p}^{\mathrm{b}}$ \\
\hline $\begin{array}{l}\text { Age, yrs, } \\
\text { mean (SD) }\end{array}$ & $\begin{array}{l}59.0(14.9) 14 \\
(53.8)\end{array}$ & $\begin{array}{l}57.4(18.9) 8 \\
(35.9)\end{array}$ & $\begin{array}{l}50.7(20.6) 12 \\
(57.1)\end{array}$ & $\begin{array}{l}57.7(15.0) 14 \\
(61.5)\end{array}$ & NS NS \\
\hline $\begin{array}{l}\text { Female sex, } \\
\mathrm{n}(\%)\end{array}$ & & & & & \\
\hline $\begin{array}{l}\text { Diagnosis } \\
\text { MPA, n (\%) } \\
\text { GPA, n }(\%) \\
\text { EGPA, n }(\%)\end{array}$ & $\begin{array}{l}17(65.4) 5 \\
(19.2) 4(15.4)\end{array}$ & $\begin{array}{l}10(76.9) 3 \\
(23.1) 0\end{array}$ & $\begin{array}{l}9(42.9) 12 \\
(57.1) 0\end{array}$ & $\begin{array}{l}19(48.7) 16 \\
(41.0) 4(10.3)\end{array}$ & 0.05 \\
\hline
\end{tabular}




\begin{tabular}{|c|c|c|c|c|c|}
\hline & $\begin{array}{l}\text { Monophasic } \\
(\mathrm{n}=26)\end{array}$ & $\begin{array}{l}\text { Remitting } \\
(\mathrm{n}=13)\end{array}$ & $\begin{array}{l}\text { Persistent } \\
(\mathrm{n}=21)\end{array}$ & $\begin{array}{l}\text { Recurrent } \\
(\mathrm{n}=39)\end{array}$ & $\mathrm{p}^{\mathrm{b}}$ \\
\hline $\begin{array}{l}\text { ANCA } \\
\text { specificity } \\
\text { Anti-MPO, n } \\
(\%) \text { Anti-PR3, n } \\
(\%)\end{array}$ & $23(88.5) 3(11.5)$ & $11(84.6) 2(15.4)$ & $9(42.9) 12(57.1)$ & $\begin{array}{l}24(61.5) 15 \\
(38.5)\end{array}$ & 0.004 \\
\hline $\begin{array}{l}\text { Clinical } \\
\text { features } \\
\text { Constitutional } \\
\text { symptoms, n } \\
\text { (\%) Fever, n } \\
\text { (\%) Anemia, n } \\
\text { (\%) Micro- } \\
\text { haematuria, n } \\
\text { (\%) Renal } \\
\text { failure, n (\%) } \\
\text { Alveolar } \\
\text { haemorrhage, } \\
\text { n (\%) } \\
\text { Pulmonary } \\
\text { infiltrates, n } \\
\text { (\%) } \\
\text { Pulmonary } \\
\text { nodules, n (\%) } \\
\text { Mononeuritis } \\
\text { multiplex, n } \\
\text { (\%) CNS } \\
\text { involvement, n } \\
\text { (\%) ENT } \\
\text { involvement, n } \\
\text { (\%) Purpura, } \\
\text { n (\%) } \\
\text { Arthritis, n } \\
\text { (\%) Ocular } \\
\text { involvement, n } \\
\text { (\%) }\end{array}$ & $\begin{array}{l}22(84.6) 15 \\
(57.7) 22 \\
(84.6) 16 \\
(61.5) 16 \\
(61.5) 7(26.9) \\
6(23.1) 2(7.7) \\
5(19.2) 2(7.7) \\
6(23.1) 2(7.7) \\
13(50.0) 0\end{array}$ & $\begin{array}{l}9(69.2) 5 \\
(38.5) 12 \\
(92.3) 11 \\
(84.6) 9(69.2) \\
2(15.4) 03 \\
(23.1) 1(7.7) 0 \\
2(15.4) 3 \\
(23.1) 3(23.1) \\
1(7.7)\end{array}$ & $\begin{array}{l}17(81.0) 11 \\
(52.4) 21(100) \\
16(76.2) 14 \\
(66.7) 6(28.6) \\
5(23.8) 5 \\
(23.8) 4(19.0) \\
1(4.8) 10 \\
(47.6) 5(23.8) \\
14(66.7) 3 \\
(14.3)\end{array}$ & $\begin{array}{l}24(61.5) 23 \\
(59.0) 29 \\
(74.4) 25 \\
(64.1) 21 \\
(53.8) 13 \\
(33.3) 11 \\
(28.2) 10 \\
(25.6) 6(15.4) \\
2(5.1) 15 \\
(38.5) 4(10.3) \\
19(48.7) 6 \\
(15.4)\end{array}$ & $\begin{array}{l}\text { NS NS } 0.05 \\
\text { NS NS NS NS } \\
\text { NS NS NS NS } \\
\text { NS NS NS }\end{array}$ \\
\hline $\begin{array}{l}\text { Treatment } \\
\text { Cyclophos- } \\
\text { phamide, n } \\
\text { (\%) } \\
\text { Azathioprine, } \\
\text { n (\%) } \\
\text { Mycophenolic } \\
\text { acid, n (\%) } \\
\text { Methotrexate, } \\
\text { n (\%) Plasma- } \\
\text { pheresis, n (\%) } \\
\text { Rituximab, n } \\
(\%)\end{array}$ & $\begin{array}{l}18(69.2) 10 \\
(38.5) 3(11.5) \\
010(38.5) 10 \\
(38.5)\end{array}$ & $\begin{array}{l}12(92.3) 6 \\
(46.2) 3(23.1) \\
01(7.7) 2 \\
(15.4)\end{array}$ & $\begin{array}{l}19(90.5) 9 \\
(42.9) 7(33.3) \\
2(9.5) 3(14.3) \\
6(28.6)\end{array}$ & $\begin{array}{l}29(74.4) 14 \\
(35.9) 7(17.9) \\
10(25.6) 3 \\
(7.7) 14(35.9)\end{array}$ & $\begin{array}{l}\text { NS NS NS } \\
0.0070 .009 \text { NS }\end{array}$ \\
\hline
\end{tabular}




\begin{tabular}{|c|c|c|c|c|c|}
\hline & $\begin{array}{l}\text { Monophasic } \\
(\mathrm{n}=26)\end{array}$ & $\begin{array}{l}\text { Remitting } \\
(\mathrm{n}=13)\end{array}$ & $\begin{array}{l}\text { Persistent } \\
(\mathrm{n}=21)\end{array}$ & $\begin{array}{l}\text { Recurrent } \\
(\mathrm{n}=39)\end{array}$ & $\mathrm{p}^{\mathrm{b}}$ \\
\hline $\begin{array}{l}\text { Outcome } \\
\text { Follow-up, yrs, } \\
\text { median (IQR) } \\
\text { Clinical } \\
\text { relapse }{ }^{\mathrm{a}} \text {, n (\%) } \\
\text { Worsening }_{\text {renal function, }} \\
\text { n (\%) } \\
\text { End-stage } \\
\text { renal disease, } \\
\text { n (\%) -ESRD } \\
\text { at baseline, n } \\
\text { (\%) -ESRD } \\
\text { during } \\
\text { follow-up, n } \\
\text { (\%) Mortality, } \\
\text { n (\%) } \\
\text { Mortality } \\
\text { related to } \\
\text { vasculitis, n } \\
\text { (\%) }\end{array}$ & $\begin{array}{l}5.7(3.3) 6 \\
(23.1) 07 \\
(26.9) 6(23.1) \\
1(3.8) 6(23.1) \\
2(7.7)\end{array}$ & $\begin{array}{l}7.1(7.5) 4 \\
(30.8) 01(7.7) \\
01(7.7) 4 \\
(30.8) 3(23.1)\end{array}$ & $\begin{array}{l}9.6(7.5) 15 \\
(71.4) 2(9.5) 3 \\
(14.3) 03 \\
(14.3) 5(23.8) \\
8(38.1)\end{array}$ & $\begin{array}{l}8.6(8.0) 34 \\
(87.2) 3(7.7) 8 \\
(20.5) 2(5.1) 6 \\
(15.4) 14 \\
(35.9) 13 \\
(33.3)\end{array}$ & $\begin{array}{l}0.07<0.001 \\
0.06 \text { NS } 0.01 \\
\text { NS NS NS }\end{array}$ \\
\hline
\end{tabular}

a [?]1 clinical relapses during follow-up. ${ }^{\mathrm{b}} \mathrm{Chi}$ square (categoric variables) or ANOVA (continuous variables). NS: not significant. Anti-MPO: anti-myeloperoxidase. Anti-PR3: anti-proteinase-3. MPA: microscopic polyangiitis. GPA: granulomatosis with polyangiitis. EGPA: eosinophilic granulomatosis with polyangiitis. ESRD: end-stage renal disease. IQR: interquartile range. ENT: ear, nose, throat. CNS: central nervous system.

Table 3. Variables associated with clinical relapses in GPA amd MPA $(n=91)$

\begin{tabular}{|c|c|c|}
\hline & $\begin{array}{l}\text { Univariate analysis Hazard } \\
\text { ratio }(95 \% \mathrm{CI})\end{array}$ & $\mathbf{p}$ \\
\hline Age Female sex & $0.99(0.97-1.01) 0.94(0.56-1.56)$ & 0.190 .82 \\
\hline Diagnosis MPA GPA & $11.90(1.12-3.22)$ & 0.02 \\
\hline Antigenic specificity & $12.34(1.38-3.97)$ & 0.002 \\
\hline \multicolumn{3}{|l|}{ Anti-MPO Anti-PR3 } \\
\hline ANCA pattern Monophasic & $10.91(0.26-3.24) 3.36$ & 0.880 .010 .001 \\
\hline Remitting Persistent Recurrent & $(1.29-8.79) 4.31(1.78-10.42)$ & \\
\hline Clinical features & $0.65(0.36-1.16) 0.63(0.37-1.09)$ & $\begin{array}{llllll}0.15 & 0.10 & 0.99 & 0.28 & 0.04 & 0.78\end{array}$ \\
\hline Constitutional symptoms Fever & $0.99(0.40-2.50) 0.73(0.42-1.29)$ & $\begin{array}{llllll}0.10 & 0.49 & 0.36 & 0.09 & 0.002 & 0.61\end{array}$ \\
\hline Anemia Microhaematuria Renal & $0.58(0.34-0.98) 1.09(0.62-1.91)$ & 0.030 .03 \\
\hline failure Alveolar haemorrhage & $1.66(0.90-3.06) 1.24(0.67-2.27)$ & \\
\hline Pulmonary infiltrates & $1.40(0.68-2.87) 2.83(0.86-9.29)$ & \\
\hline Pulmonary nodules & $2.36(1.38-4.03) 1.22(0.57-2.58)$ & \\
\hline $\begin{array}{l}\text { Mononeuritis multiplex CNS } \\
\text { involvement ENT involvement } \\
\text { Purpura Arthritis Ocular } \\
\text { involvement }\end{array}$ & $1.82(1.07-3.12) 2.34(1,10-4.99)$ & \\
\hline
\end{tabular}




\begin{tabular}{|c|c|c|}
\hline & $\begin{array}{l}\text { Univariate analysis Hazard } \\
\text { ratio }(95 \% \mathrm{CI})\end{array}$ & $\mathbf{p}$ \\
\hline Treatment Cyclophosphamide & $0.68(0.32-1.42) 1.74(1.02-2.98)$ & 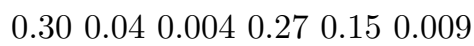 \\
\hline Azathioprine Methotrexate & $2.72(1.38-5.36) 1.41(0.77-2.60)$ & \\
\hline Mycophenolic acid & $0.50(0.20-1.27) 2.10(1.20-3.68)$ & \\
\hline Plasmapheresis Rituximab & & \\
\hline
\end{tabular}

MPA: microscopic polyangiitis GPA: granulomatosis with polyangiitis Anti-MPO: anti-myeloperoxidase. Anti-PR3: anti-proteinase

Table 4. Variables associated with clinical relapses in GPA and MPA ( $n=91)$. Multivariate analysis

\begin{tabular}{|c|c|c|c|c|c|}
\hline Model 1* & $\begin{array}{l}\text { Cox regression } \\
\text { Hazard ratio } \\
(95 \% \text { CI })\end{array}$ & $\mathbf{p}$ & Model 2* & $\begin{array}{l}\text { Cox regression } \\
\text { Hazard ratio } \\
(95 \% \text { CI })\end{array}$ & $\mathbf{p}$ \\
\hline $\begin{array}{l}\text { ANCA } \\
\text { pattern } \\
\text { Monophasic } \\
\text { Remitting } \\
\text { Persistent } \\
\text { Recurrent } \\
\text { Fever } \\
\text { Arthritis } \\
\text { Ocular } \\
\text { involvement } \\
\text { Rituximab } \\
\text { treatment }\end{array}$ & $\begin{array}{l}0.92 \\
(0.25-3.42) \\
2.94 \\
(1.08-7.99) \\
3.67 \\
(1.48-9.06) \\
0.42 \\
(0.23-0.78) \\
2.48 \\
(1.36-4.52) \\
2.80 \\
(1.22-6.44) \\
2.47 \\
(1.39-4.39)\end{array}$ & $\begin{array}{ll}0.90 & 0.030 .005 \\
0.006 & 0.003 \\
0.015 & 0.002\end{array}$ & $\begin{array}{l}\text { ANCA } \\
\text { pattern } \\
\text { Monopha- } \\
\text { sic/remitting } \\
\text { Persis- } \\
\text { tent/recurrent } \\
\text { Fever } \\
\text { Arthritis } \\
\text { Ocular } \\
\text { involvement } \\
\text { Rituximab } \\
\text { treatment }\end{array}$ & $\begin{array}{l}3.55 \\
(1.75-7.21) \\
0.42 \\
(0.23-0.79) \\
2.40 \\
(1.33-4.32) \\
2.80 \\
(1.22-6.40) \\
2.54 \\
(1.43-4.50)\end{array}$ & $\begin{array}{l}<0.0010 .006 \\
0.0040 .015 \\
0.001\end{array}$ \\
\hline
\end{tabular}

*Model 1 was based on the four described ANCA patterns. Hazard ratios of clinical relapse in remitting, persistent or recurrent ANCA patterns were compared to the monophasic pattern. Model 2 was based on two aggregated ANCA patterns. Hazard ratio of clinical relapse in persistent/recurrent ANCA patterns were relative to the monophasic/remitting pattern.

Table 5. Variables associated with worsening renal failure in anti-MPO vasculitis. Univariate analysis $(\mathrm{n}=52)^{\mathrm{a}}$.

\begin{tabular}{lll}
\hline & $\begin{array}{l}\text { Univariate analysis Hazard } \\
\text { ratio }(95 \% \mathrm{CI})\end{array}$ & $\mathbf{p}$ \\
\hline Age Female sex & $1.00(0.97-1.04) 0.95(0.40-2.27)$ & 0.880 .92 \\
Diagnosis GPA MPA & $11.83(0.42-7.96)$ & 0.42 \\
ANCA pattern Monophasic & $11.93(0.32-11.59) 3.45$ & 0.470 .150 .06 \\
Remitting Persistent Recurrent & $(0.63-18.87) 4.26(0.95-19.07)$ &
\end{tabular}




\begin{tabular}{llll}
\hline & \multicolumn{1}{l}{ Univariate analysis Hazard } & & \\
& ratio $(95 \% \mathrm{CI})$ & $\mathbf{p}$ & \\
\hline Clinical features & $0.33(0.14-0.78) 0.33(0.13-0.86)$ & 0.010 .020 .780 .400 .710 .83 \\
Constitutional symptoms Fever & $1.34(0.18-10.05) 1.88$ & 0.690 .230 .220 .890 .010 .93 \\
Anemia Microhaematuria & $(0.44-8.07) 1.18(0.48-2.94) 0.85$ & & \\
Alveolar haemorrhage & $(0.20-3.72) 1.52(0.20-11.51)$ & & \\
Pulmonary infiltrates & $0.04(0.00-8.13) 0.28(0.04-2.12)$ & & \\
Pulmonary nodules & $0.87(0.11-6.67) 0.25(0.08-0.76)$ & & \\
Mononeuritis multiplex ENT & $1.07(0.25-4.62)$ & & \\
involvement Purpura Arthritis & & & \\
Ocular involvement & & & \\
Treatment Cyclophosphamide & $0.38(0.10-1.47) 0.54(0.21-1.41)$ & 0.160 .210 .450 .710 .380 .10 \\
Azathioprine Methotrexate & $0.04(0.00-141.05) 0.83$ & & \\
Mycophenolic acid & $(0.30-2.29) 1.76(0.50-6.24) 2.18$ & & \\
Plasmapheresis Rituximab & $(0.86-5.52)$ & & \\
\hline
\end{tabular}

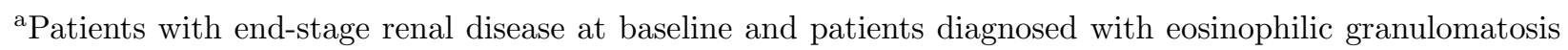
with polyangiitis were excluded from this analysis.

MPA: microscopic polyangiitis. GPA: granulomatosis with polyangiitis.

Table 6. Variables associated with worsening renal failure in anti-MPO vasculitis $(n=52)^{a}$. Multivariate analysis

\begin{tabular}{|c|c|c|c|c|c|}
\hline Model 1* & $\begin{array}{l}\text { Cox regression } \\
\text { Hazard ratio } \\
(95 \% \text { CI })\end{array}$ & $\mathbf{p}$ & Model 2* & $\begin{array}{l}\text { Cox regression } \\
\text { Hazard ratio } \\
(95 \% \text { CI })\end{array}$ & $\mathbf{p}$ \\
\hline $\begin{array}{l}\text { ANCA } \\
\text { pattern } \\
\text { Monophasic } \\
\text { Remitting } \\
\text { Persistent } \\
\text { Recurrent } \\
\text { Arthritis }\end{array}$ & $\begin{array}{l}1.92 \\
(0.32-11.62) \\
3.39 \\
(0.62-18.62) \\
5.68 \\
(1.24-26.05) \\
0.19 \\
(0.06-0.62)\end{array}$ & $\begin{array}{l}0.480 .160 .03 \\
0.006\end{array}$ & $\begin{array}{l}\text { ANCA } \\
\text { pattern } \\
\text { Monopha- } \\
\text { sic/remitting } \\
\text { Persis- } \\
\text { tent/recurrent } \\
\text { Constitu- } \\
\text { tional } \\
\text { symptoms } \\
\text { Arthritis }\end{array}$ & $\begin{array}{l}3.10 \\
(1.11-8.64) \\
0.40 \\
(0.16-1.00) \\
0.24 \\
(0.08-0.75)\end{array}$ & $\begin{array}{lll}0.03 & 0.05 & 0.01\end{array}$ \\
\hline
\end{tabular}

*Model 1 was based on the four described ANCA patterns. Hazard ratios of worsening renal failure in remitting, persistent or recurrent ANCA patterns are relative to the monophasic pattern. Model 2 was based on two aggregated ANCA patterns. Hazard ratio of worsening renal failure in persistent/recurrent ANCA patterns is relative to the monophasic/remitting pattern. 

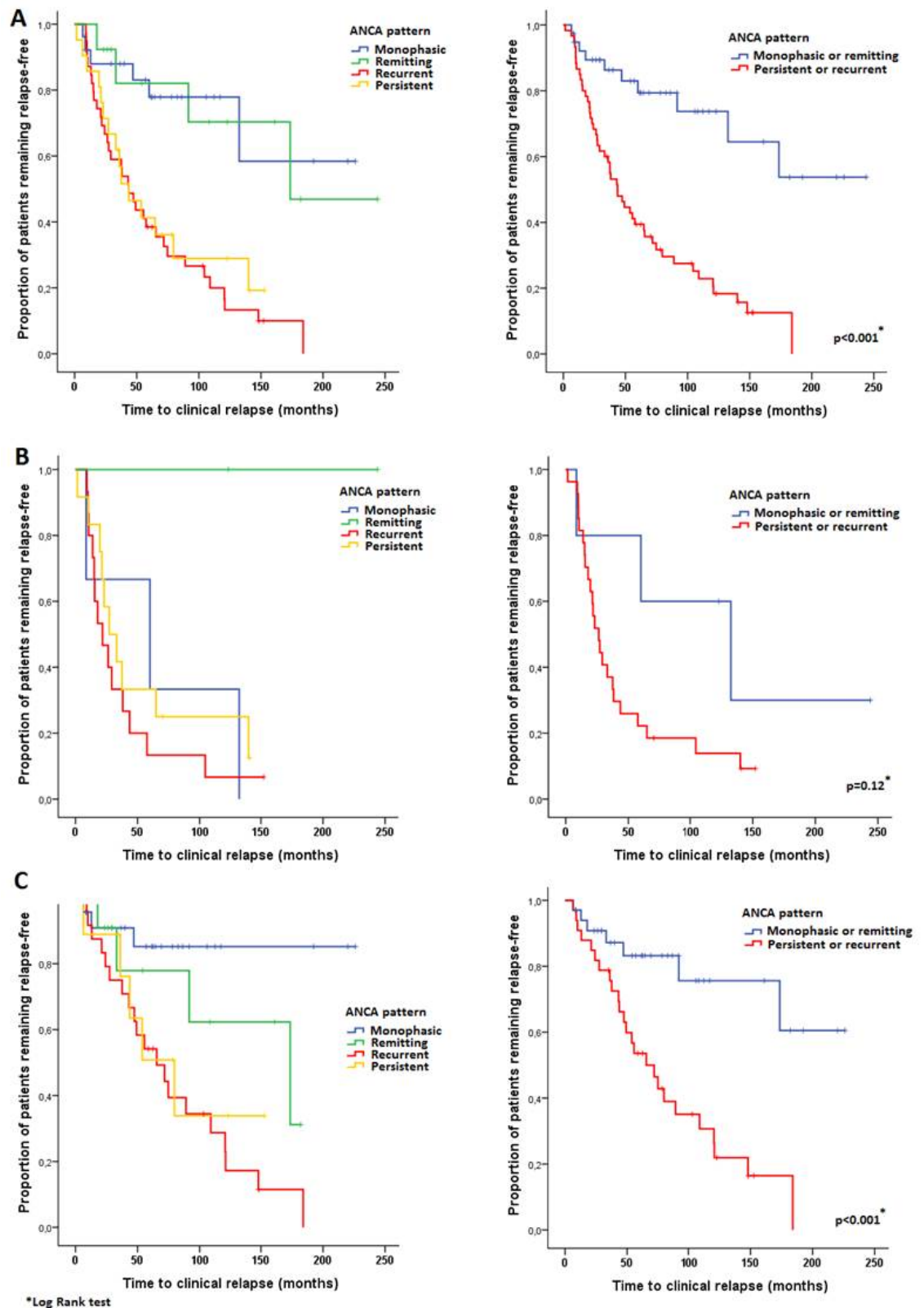

